\title{
Research on Springs *
}

$\mathrm{T}^{\mathrm{H}}$ HERE are few people at the present time who are not interested in springs of some kind. That large section of the general public which uses the automobile, either for business or pleasure, generally finds at some time or other that the breakage of a circular spring round a valve stem or of a flat spring on the suspension system may be responsible for an amount of inconvenience out of all proportion to the seriousness of the accident.

Even government departments are liable to such troubles, and both during the War and for some years after, the Chief Inspector of Mechanical Transport of the War Office directed attention to the unsatisfactory position in relation to the design and performance of laminated springs for mechanically propelled vehicles. Failures of valve springs in aircraft engines were reported by the Air Ministry, and both the Admiralty and the War Office were experiencing difficulties with spiral springs. In the motor-car trade there was much trouble associated with the use of valve springs on high-speed car engines and generally where the working conditions were severe.

Due to the representations made to the Department of Scientific and Industrial Research, a Springs Research Committee was appointed in 1922, with the main object of carrying out such inquiries and researches as would result in the improvement of the materials and design of laminated and spiral springs. Since that time much work has been done by the different sections of the Committee, and the results of their investigations have been published from time to time. In the Report just issued, a general survey is made of the whole of the Committee's work and the definite conclusions to be drawn from it are sum. marised.

It will be found that the field covered by the Com. * Department of Scientifle and Industrial Research. Report of
the Springs Research Committee. Pp. iv +75 . (London: H.M. the Springs Research Committee.
Stationery Office, 1931.) 1 s. 3a. net. mittee is a very wide one. Naturally the researches into the properties of spring material bulk largely in the Report, but much work has also been done in perfecting methods of testing complete springs and of finding the oscillating and loading conditions to which springs are subject under road service.

The most striking conclusion reached is that, with springs as ordinarily manufactured and used, the high stress-resisting properties of which the spring material is capable are not realised. Spring material of many types has been tested under a wide variety of conditions, and has shown itself to be capable of resisting wide ranges of repeated stress for long periods. When, however, this material is converted into springs, breakage occurs at stress ranges of from about onequarter to one-half of what should have been resisted.

The explanation given for this surprising discrepancy is that a surface weakness is developed during the heat treatment and other manufacturing processes. Experiment has shown that this deleterious surface layer is very thin, and that the full resistance value of the material can be regained by machining about one-sixteenth of an inch from the surface of the spring. With spring steel wire the same conclusions hold; in all grades of wire tested the 'surface effect' was evident even when the wire had been manufactured under special conditions. It is, therefore, not surprising that the Committee recommends that manufacturing methods should be developed for the production of spring steel in plates or wire which shall utilise the full intrinsic fatigue strength of the material.

The Report should be of value both to the user and manufacturer of springs. It is an excellent illustration of the value of co-operation between science and industry, since, largely as a result of a systematic and detailed programme of research, both an explanation and a remedy have been found for a trouble responsible in the past for many serious consequences.

\section{The Dating of Pueblo Ruins in Arizona}

HXCAVATIONS undertaken on four sites in Arizona, Kin Tiel and Kokopnyama, north of the Little Colorado River, and Pinedale and Showlow in the forested area to the south, have furnished evidence which will now make it possible to date the phases of Pueblo culture with accuracy over a period of 1200 years.

The researches in dendro-chronology, as applied to Pueblo archæology, which were undertaken by $\mathrm{Dr}$. A. E. Douglass at the invitation of the National Geographic Society while the famous ruins of Pueblo Bonito were under excavation by one of its expeditions, have established two sequences of ring records in the course of three 'Beam Expeditions' to the Pueblo area.

For one of these the coincidence and overlap of the annual rings in pine log beams from the still inhabited Hopi village of Oraibi were worked out, in accordance with the system elaborated by Dr. Douglass, from the normal and subnormal growth of rings according to rainfall, to show a complete historical sequence back to about A.D. 1260. By the same method a prehistoric sequence was established, extending back over 580 years on the evidence of beams from the Citadel ruins at Mesa Grande and Puoblo Bonito, thus going back into the third of the five periods of Pueblo culture, of which the fifth and last extends from the Spanish conquest in the sixteenth century to the present day.

No. 3250, VoL. 129]
The excavations at the four sites mentioned were undertaken in the hope of finding a link which would connect the prehistoric and historic sequences and substitute an absolute dating for the relative dating of the earlier period. It was thought that such a link would be provided by the study of a certain transient type of Pueblo pottery, for which no date was available, but which, it was thought, would furnish a clue to ruins immediately antedating the still inhabited Oraibi village. A reconnaissance of twenty prehistoric villages was made before the four sites in question were selected.

'The accounts of the chronological and archæological results obtained by Dr. Emil W. Haury and Mr. Lyndon Hargrave at Showlow and Pinedale, and by the latter at Kin Tiel and Kokopnyama (Smithsonian Miscellaneous Collections, vol. 82, No. 11), provide some indication of the far-reaching effect of the application of an absolute and accurate chronology to the investigation of Pueblo antiquities. So far as the main objective of the expedition is concerned, timbers were recovered which linked together the two date sequences and carried back the tree ring calendar to A.D. 700. A beam, to which the field notation H.H. 39 has been given, was found at Showlow which proved the key beam converting the relative dating into an absolute chronology. The outer rings could be read at about A.D. 1380, while its central ring dated at A.D. 1237. The innermost rings coincided with the 